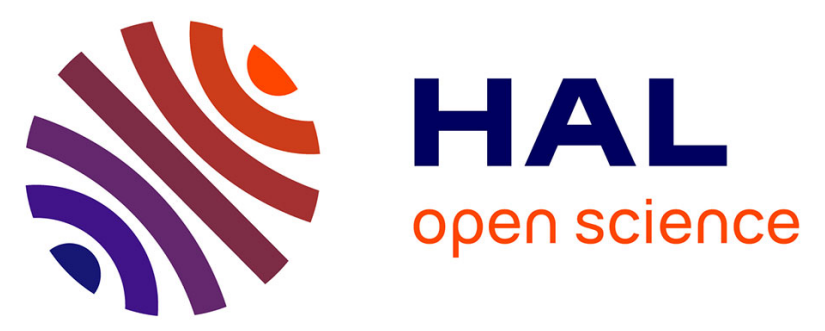

\title{
Simulation-optimisation based framework for Sales and Operations Planning taking into account new products opportunities in a co-production context
} Jean Wery, Jonathan Gaudreault, André Thomas, Philippe Marier

\section{- To cite this version:}

Jean Wery, Jonathan Gaudreault, André Thomas, Philippe Marier. Simulation-optimisation based framework for Sales and Operations Planning taking into account new products opportunities in a co-production context. Computers in Industry, 2018, 94, pp.41-51. 10.1016/j.compind.2017.10.002 . hal-01620006

\section{HAL Id: hal-01620006 https://hal.science/hal-01620006}

Submitted on 20 Oct 2017

HAL is a multi-disciplinary open access archive for the deposit and dissemination of scientific research documents, whether they are published or not. The documents may come from teaching and research institutions in France or abroad, or from public or private research centers.
L'archive ouverte pluridisciplinaire HAL, est destinée au dépôt et à la diffusion de documents scientifiques de niveau recherche, publiés ou non, émanant des établissements d'enseignement et de recherche français ou étrangers, des laboratoires publics ou privés. 


\title{
Simulation-optimisation based framework for Sales and Operations planning taking into account new products opportunities in a co-production context
}

\author{
Jean Wérya ${ }^{a}$, Jonathan Gaudreault ${ }^{\mathrm{a}}$, André Thomas ${ }^{\mathrm{b}}$, Philippe Marier ${ }^{\mathrm{a}}$ \\ ${ }^{a}$ FORAC Research Consortium, Université Laval, Québec, Canada; ${ }^{b}$ CRAN, Centre de Recherche \\ en Automatique de Nancy, Vandoeuvre-lès-Nancy, France \\ *Corresponding author. Email: jean.wery.1@ulaval.ca
}

\begin{abstract}
The North American lumber industry produces mostly commodity products (i.e. products with standard dimensions and properties). However, some customers also want products showing very specific characteristics. Because sawing involves co-production (many different types of lumbers are obtained from a single tree), sawmills do not know how the introduction of a new "speciality" product will affect quantities for the other products they also produce. We propose a simulation-optimisation based framework to tackle the kinds of problems such as these, where classical formulations cannot be used. A log breakdown simulator is used in combination with a tactical planning model in order to realise sales and operations planning. The plan gives the information to the decision maker about which orders for speciality products should be accepted, what to produce and when, as well as the equipment settings to use and the raw material to buy/consume at each period. Through an industry-inspired case study, we show how the framework can lead to substantial benefits (or savings).
\end{abstract}

KEYWORDS: Lumber industry, simulation, S\&OP, optimisation, coproduction.

\section{Introduction}

The North American softwood lumber industry produces mainly commodity products having standard dimensions and characteristics (e.g. 2 inches $\mathrm{x} 3$ inches $\mathrm{x} 8$ feet, grade 3 ). This means that products of any company are interchangeable with those of their competitors. The market of each company is considered limitless, as every product made in each sawmill can be sold on this huge market. However, prices change all year round. 
Softwood lumber sawmills show another particularity. From a given unit of raw material (log), it produces several different finished products (divergent process) at the same time (co-production). Companies try to maximise profits by using hardware with embedded software which optimises production value in real time without taking either orders into account or human intervention. The equipment analyses each log and then cuts it adequately in order to obtain the mix of products that will generate the highest possible value, knowing they can all be sold on the spot market.

In a particular situation where a sawmill receives a demand for a non-standard product (dimensions and/or characteristics), settings of the machinery have to be modified in order to 'allow' the equipment to produce this customer's specific request. However, it is unclear for the company what quantity of that product will be obtained, given the fact that the decisions of how to cut each log are made in real time by the hardware, based on the expected value of each product, with no consideration for demand. It is then difficult to predict how it will affect the rest of the production and subsequently the overall profit. Additionally, if there are several potential demands for different speciality products, the choice of the contract(s) to accept (i.e. demand to fulfil) becomes a complex combinatorial problem. Moreover, as the commodity products' prices change all year round, the company strategy should differ for each period. Likewise, when the raw material supplied (e.g. dimensions of consumed logs) changes, it is difficult to evaluate its consequences on the mix of products obtained and on the profits.

This paper proposes a decision-making framework based on simulation-optimisation to tackle these problems. It uses a sawing simulator to evaluate how the alternative modifications to the equipment settings and new supplied raw material impact the mix of products obtained. Simulation results feed a multi-period combinatorial Sales and Operations Planning (S\&OP) model. This model enables determining which orders should be accepted, what to produce and when, as well as the equipment settings to use and the raw material to buy/consume at each period. 


\section{Preliminary concepts}

\subsection{The lumber industry}

In North America, the lumber supply chain is characterised by some specificities. Logs (corresponding to felled trees that have been limbed and cut to length) are transferred from the forest to a lumber mill log yard.

Logs are processed by the sawmill according to a 'push' production system in order to produce the range of products with the highest possible market value using a fully automated process (Cid Yáñez et al. 2009). Each log generates many products at the same time (it is a divergent process with co-production). At the physical level, when a log is processed by the sawing unit, an optimiser ${ }^{1}$ decides which cutting pattern will be used in order to maximise the profitability. The goal of the optimiser is to maximise the value of the log and minimise the material losses. Since North American lumber products are normalised (they are classified by dimensions, length and grades according to the NLGA ${ }^{2}$ standard grading rules) there is a limited number of different products that can be produced. Each log is automatically sawn following the recommendations of the optimiser. The decision concerning the cutting pattern is done individually for each log. The decision is not influenced by actual customer orders. For this reason, and because it is impossible to produce a single particular product without getting some other products at the same time (co-production), it is difficult to plan production according to customer orders (Crama, Pochet, and Wera 2001).

However, logs in the yard are usually stored according to their 'class'. Each class corresponds to logs which have similar characteristics. Based on past production data, sawmills are able to estimate

\footnotetext{
${ }^{1}$ Software integrated to the hardware

${ }^{2}$ NLGA stands for National Lumber Grades Authority and is the organisation responsible for lumber grading rules and standards in Canada
} 
the quantities of each product that a log class can produce (Gaudreault 2009), as shown in Figure 1. By deciding which quantities of each log class will be sawn at each period, we then have some control over the production quantities of the different finished products we should obtain.

\subsection{Tactical planning and optimisation models}

In standard manufacturing situation, it is considered that there are three different planning levels (Anthony 1965). Blackstone (2008) names them strategic level (long-term decision making, e.g. building a new plant), tactical level (mid-term decisions, e.g. Sales and Operations Planning), and operational level (short-term production planning and scheduling).

Sales and Operations Planning (S\&OP) joins together sales, marketing, procurement, development, finance and production around plans (Vollmann, Berry, and Whybark 1984). S\&OP process can be supported by a mathematical model using linear programming. In the Canadian lumber industry, the main objectives are to determine, in an integrated way: (1) the quantities of raw material to use and which ones to buy, (2) the optimal mix of products to make, (3) the transformation process to use, (4) the whole set of contracts/market opportunities that the sawmill should take. S\&OP planning horizon is generally one year (twelve one-month periods or 52 one-week periods). Planning takes into account production lead time, transfer lead times between sawmills and distribution centres, production capacities with the objective of maximising profits. It allows sawmills to foresee the production of its different units, to size resource capacities (humans/machines) if needed and inventories. S\&OP replanning is generally carried on once a month and gives the guiding lines and objectives of the operational planning level.

In order to establish a tactical plan, the particularities/physical constraints of the plant must be taken into account. For example, as decisions about how to cut the logs are made in real time by the hardware, it would be illusory to suppose that this decision can be made by the tactical planning model. However, the tactical planning model can be used to decide which settings will be given to 
the hardware, and the quantities of each log class that will feed the sawing unit at each period. In order to do this, we have to 'feed' the tactical planning model with data that allows predicting what the production will be for a given set of hardware configurations (settings) and raw material. We can extract this data from the ERP system of the company.

Among those authors who have worked on the specific problem of softwood lumber production planning, Maness and Adams (1993) have proposed a mixed programming model that simultaneously determines the optimal bucking and sawing policies based on demand and final product price (integration of stem bucking and log sawing). This model was later modified to handle several periods (Maness and Norton 2002). These works focus on the identification of new cutting patterns/policies.

Taking a more global view of the supply chain, Singer and Donoso (2007) presented a model for optimising planning decisions in the sawmill industry. The objective was to demonstrate how collaboration can benefit the partners, by transferring timbers and using the competitive advantages of each. Bajgiran, Kazemi Zanjani, and Nourelfath (2014), Kong and Rönnqvist (2014) use a Mixed Integer Programming model to plan the whole supply chain from harvesting to the delivery. Marier et al. (2014) developed a mathematical model that allows making the Sales and Operations Planning of one (or more) sawmills. They considered the three units of sawmills (sawing, drying and wood finishing) and their capacity constraints. It considers yearly price fluctuations of sawmills' finished products and several raw material sources. The model is able to modulate production and inventory levels and they show that this can significantly increase sales revenue without changing the capacities.

For more details about other models and planning methods used in the forest products industry, the reader could refer to D'Amours, Rönnqvist, and Weintraub (2008), Rönnqvist (2003), and Shahi and Pulkki (2013). 


\subsection{Current limits of tactical planning approaches}

Even in the North American commodity products context, it happens a client expresses needs for high volumes of a customised product (specific dimensions and/or grade). The automated sawing hardware is then configured with settings allowing it to produce the new product. The internal optimiser will still try to maximise the value it gets from each log. Thus, it will produce both the new product and the other commodity products. Having no historical data available concerning the 'new' process, we do not know how it will affect production for other co-products. Therefore, it is not possible to use a classic tactical planning approach to decide if the new market opportunity should be captured, as we do not have the production matrices (quantities of each product obtained if this equipment is set up with some settings). This brings uncertainty regarding the profitability of the new product. While at first it may seem very profitable to sell a product at a much higher price than normal commodity lumber, the impact on other products quantities may bring an overall loss of profits. In a similar way, if logs from a new supplier had never been processed by the sawmill, it is difficult to know the mix of products given by this new 'log class' as well as the benefits and losses that it can bring. Consequently, it is nowadays quite a delicate issue to change sawmill suppliers, to decide which log classes to buy, or even the way logs are classified.

To summarise, it is very difficult for the company to comply with specific needs of a client and it is even more difficult to know if it will be profitable. Most sawmills use expensive trial and error approaches to find out if it is profitable to make a given speciality product. However, it is also possible to use simulation or an approach combining simulation and optimisation (Shahi and Pulkki 2013), as we detail in the next sections.

\subsection{Log breakdown simulation}

Simulation is usually employed when the reality is so complex that it is difficult to represent it by an optimisation model. It is a means to mimic the reality and a technique making it possible to 
proceed to experiments (Turban, Sharda, and Delen 2011). Regarding the wood industry, there are several simulators specialised in log breakdown like SAWSIM, SIMSAW, Autosaw, Optsaw, Saw2003, WoodCIM or Optitek.

They can simulate the sawing of a given log (represented by a 3D scan) by a plant modelled in great detail (machines, configurations, etc.) (Sampson 1990; Lindner 2014). For example, the Optitek simulator provides the amount of each finished product (mix of products) from the logs consumed in the mill (Figure 2). It very precisely models the different machines of the mill and we can modify the settings of the machines to see how it will affect the production.

\subsection{The use of simulation and optimisation in the forest products industry}

Ladier et al. (2014) identifies four different types of relationships between simulation and optimisation: (1) integration of an optimisation model within a simulation model, (2) use of a simulation model to generate data that will further be used by an optimisation model, (3) use of simulation to evaluate precisely (and stochastically) the value of an optimisation model output, (4) use of a simulation model integrated within an optimisation model.

In the forest-products industry, simulation is often used to obtain information which is then used to feed decision-making models (2). Sinclair and Erasmus (1992) use SIMSAW software to get data about different trees/logs cutting patterns for operational planning purpose. Wessels et al. (2006) developed a package that combines linear and mixed-integer programming techniques in order to make operational, tactical or strategic planning of forest harvesting and sawmilling operations using SIMSAW simulation results. Arabi et al. (2012) do the tactical planning for harvesting, wood transportation and sawmilling at the same time. They combined two software (FPInterface for simulation and Optitek for log breakdown simulation) to an optimisation model.

Simulation can also be used to verify whether a plan given by an optimisation model is adequate or 
not (3). For example, Jerbi, Gaudreault et al. (2012) first make a tactical plan using an optimisation model for a complex lumber supply chain. They then use simulation to verify the impacts of the tactical planning at the operational level. Similarly, Dumetz, Gaudreault et al. (2016) use discrete event simulation to compare different planning strategies in the North American softwood lumber industry context.

Simulation is an interesting tool for evaluating and comparing different scenarios (e.g. to compare factory designs). When the number of possible scenarios is such that it could take a year or more to simulate all the alternatives i.e. the available computational time is not sufficient to simulate all the possible scenarios, one generally falls back on a set of techniques called simulation-optimisation where simulation is used inside an optimisation model (4) (Carson and Maria 1997).

\subsection{Simulation-optimisation in classical context}

A simulation-optimisation problem can be formalised as follows. It is an optimisation problem for which one seeks to minimise (or maximise) an objective function $f(x \in X)$, where $x$ is a vector representing the decision variables and $X$ the space of possible scenarios (Fu 2015):

$$
\operatorname{Max}_{x \in X} f(x)
$$

However, $f$ is not directly evaluable (because it implies a random phenomenon) but its value can be estimated by simulation. The function $f$ can thus be represented as the expectation of a simulation result for an output random variable $Y(x, \xi)$, where $\xi$ is the set of random numbers of a simulation:

$$
f(x)=E[Y(x, \xi)]
$$

In practice, we have a simulation function $S\left(x, \xi_{i}\right)$ which returns, for a given scenario $x$ and a 
realisation $\xi_{i}$ of the random parameters, a vector of metrics used to evaluate this realisation of the scenario. An objective function $F\left(S\left(x, \xi_{i}\right)\right)$ takes this simulation result as an input and evaluates the value according to the criterion established by the decision maker. Each scenario will be evaluated for $n$ realisations of the random parameters. Each of these simulations will constitute a replication. We will therefore assume that:

$$
f(x) \approx F(S(x, \xi))=\frac{1}{n} \sum_{i=1}^{n} F\left(S\left(x, \xi_{i}\right)\right)
$$

And we will seek to maximise this value:

$$
\underset{x \in X}{\operatorname{Max}} F(S(x, \xi))
$$

For example, let us assume the problem of designing a plant. We are looking for the design that will maximise the plant's performance $F$. For each possible configuration of the system (i.e. each different design), we define a simulation scenario $x \in X$. Some processes or even demand are not constant and have a random part. For each scenario $x$, we can simulate the behaviour of the system several times (with different random numbers $\xi$ for each replication corresponding to different machine failure rates or delivery times). A number of replications $n$ is to be made in order to estimate the performance $F$.

Simulation-optimisation techniques are used to find the best possible scenario when computational time is not long enough to simulate all scenarios. Figure 3 describes the process in general. Basically, a replication of a scenario $x_{i}$ is first evaluated through simulation. The simulation result $S\left(x_{i}, \xi_{j}\right)$ is used to estimate the performance $F\left(S\left(x_{i}, \xi_{j}\right)\right)$ of the scenario. This is the input of a search procedure that will identify the next scenario to simulate, e.g. $\left(x_{i+1}, \xi_{j}\right)$ or $\left(x_{i}, \xi_{j+1}\right)$. The most used 
techniques are: Ranking and Selection (Goldsman and Nelson 1994; Law 2007), Response Surface Methodology, Stochastic Approximation, Sample Average Approximation and Random Search Methods. Fu (2015) reviews these techniques and the reader can refer to it for further information.

\section{Simulation-optimisation based framework for scenario combinations selection}

In this section we propose a framework that combines scenarios in order to find the best solution. In classical simulation-optimisation, one looks for the scenario $x \in X$ maximising an objective function. However in this research, we rather seek the 'combination' of scenarios that jointly maximise an objective function. Let's imagine that instead of designing one plant, we have to build several factories that will jointly generate the best profits for the company. Rather than look for the best configuration of a system, we look for a set $\bar{X} \subseteq X$ of configurations for this system which, together, give the best performance. Because of the combinatorial aspects of the supply chain and markets, the plants to build are not necessarily the ones that would perform best if they were to be exploited alone. Moreover, constraints like an upper bound over the size of $\bar{X}$ may exist such as $|\bar{X}|<\theta$

If we had access to a simulator capable of simulating the full supply chain, the classical formation described in the previous section would do the job (although each simulation run would be huge).

However, evaluating how a set of plants would perform on a market can be computed easily using a mathematical programming model $g(\bar{X})$, the model deciding which mill will deserve which customers, etc.

Moreover, when provided with more than $\theta$ configuration, this model can easily select the ones that perform best together.

We represent this problem in the following way: 


$$
\underset{\bar{X} \subseteq X|| \bar{X} \mid \leq \theta}{\operatorname{Max}} g(\bar{X})
$$

With

$$
g(\bar{X}) \approx G(\{S(x, \xi)\} \mid x \in \bar{X})
$$

Where $S(x, \xi)$ is the vector of the results of simulation $S\left(x, \xi_{i}\right)$ with $i=1, \ldots, n, \bar{X}$ is the set of sought scenarios and must maximally be of size $\theta, G(\{S(x, \xi)\} \mid x \in \bar{X})$ is the function that allows evaluating a set of scenarios. Figure 4 illustrates this approach.

\section{Application of the framework to the softwood lumber industry}

The framework proposed in the previous section can be used for tactical Sales and Operations Planning in a situation where transformation process data does not exist (either because the plant never had the opportunity to transform a particular raw material or because a specific finished product has never been made).

A sawmill simulation component is used to evaluate the impact of different plant configurations associated with the production of new specialised products and new raw material suppliers. An optimisation S\&OP model determines which combination of configurations should be used during each production period, as well as the raw material to use, the quantities and type of raw material to consume, the quantities of finished products to expect (that is, the optimal mix of products to make) and the contracts/market opportunities that the sawmill should capture. Figure 5 details this process. It uses the Optitek sawing simulator and the S\&OP optimisation model from Marier et al. (2014). A search procedure can be used in order to find the next scenario to simulate.

Its application to the softwood lumber mill planning is based on the methodology developed by 
Wery et al. (2014)_In order to implement the principle described in Figure 5, information regarding inputs of the optimisation model and a way of generating scenarios are needed. We first need to prepare the simulation scenarios, i.e. model the plant within the simulator, the different machine configurations that can be used, the different raw materials that the company could buy and the specifications of the finished products that are possible to make. Simulation of the scenarios enables us to get some information about transformation (i.e. characteristics and quantity of finished products) as well as the time needed to transform each of the logs into lumbers, for each valid scenario/combination of < plant configuration, raw material provenance and mix of possible products to make> defined. For the configurations/raw materials/mix of products already tested in past operations of the plant, it is possible to get similar data by extracting them from the manufacturing execution system of the company. As for the search procedure, in our experiments, we used a very simple ad hoc approach for the case instead of a complex feedback loop. An expert from the industry has generated many different scenarios and sorted them according to their expected "usefulness".

The optimisation model (Figure 6) is able to establish, for each period, the configuration of the plant to use, the raw material to use and the products that should be produced.

Formally, input data for the planning model of Marier et al. (2014) which are obtained from the simulation results and from historical data (1) are the following: consumption (volume) of each log class $b$ which can be sawn in one time unit according to the sawing configuration $y\left(v c_{b, y}\right)$, the volume $v t_{p, b, y}$ of product $p$ that is expected when sawing one volume unit of log class $b$ using sawing configuration $y$, the volume $v s_{p, z}$ of product $p$ which can be dried in one time unit using kiln configuration $z$, the volume $v r_{p, x}$ of product $p$ which can be planed in one time unit using wood finishing configuration $x$, the volume $v o_{p, x}$ of product $p$ obtained after wood finishing operation for the wood finishing configuration $x$. 
In order to run the model, it is also necessary to have information (2) about the volumes $v a_{b, t}$ of $\log$ classes $b$ available for replenishment at period $t$, as well as procurement costs $c a_{b, t}$.

Further, tactical planning takes into account available capacity (3) for each period $t$ at the sawing unit $\left(d t_{t}\right)$, drying unit $\left(d s_{t}\right)$ and wood finishing unit $\left(d r_{t}\right)$. The maximal inventory $i_{p, t}$ for each product $p$ that can be stored at period $t$ and the maximal inventory $i_{b, t}$ for each $\log$ class $b$ are also important for tactical planning.

It is necessary to obtain information about the market (4) in order to decide which products should be sold, when and at what price. We use $p v_{p, t}$, the expected selling price of product $p$ at period $t$, the minimum quantity $q m_{p, t}$ of product $p$ to sell at period $t$ corresponding to agreements already signed and the maximum quantity $q n_{p, t}$ of product $p$ which could be sold at period $t$ on the market (really important for new speciality products).

Thus, we can get the volume $V T_{b, t}$ of $\log$ class $b$ sawn at period $t$, the volume $V R_{p, t}$ of product $p$ planed at period $t$, the volume $V T_{p, t}$ of product $p$ obtained after sawing at period $t$, the volume $V S_{p, t}$ of product $p$ dried at period $t$, the volume $V O_{p, t}$ of product $p$ obtained after wood finishing at period $t$, the volume $V V_{p, t}$ of sales of product $p$ at period $t$, inventory $I F_{p, t}$ of product $p$ at period $t$, inventory $I F_{b, t}$ of $\log b$ at period $t$, the sawing configuration $y$ used at period $t$, the kiln configuration $z$ used at period $t$, the wood finishing configuration $x$ used at period t, the supply cost $C A_{b, t}$ for $\log$ class $b$ at period $t$, the incomes $R_{p, t}$ for sales of product $p$ at period $t$, as well as the total incomes $R_{t}$ at period $t$.

The multi-period plan enables maximising global profit i.e. incomes minus costs for the entire planning horizon. Let $\boldsymbol{T}$ be the number of periods within the planning horizon, the objective function to maximise is then:

$$
\operatorname{Max} \sum_{t}^{T}\left(R_{t}-\left(C T_{t}+C S_{t}+C R_{t}+C I_{t}+C A_{t}\right)\right)
$$


With:

- $R_{t}$, the global incomes at period $t$

- $C T_{t}$, the sawing cost at period $t$;

- $C S_{t}$, the drying cost at period $t$;

- $C R_{t}$, the wood finishing costs at period $t$;

- $C I_{t}$, the inventory cost at period $t$;

- $C A_{t}$, the total supply cost at period $t$.

\section{$5 \quad$ Industrial case study}

\subsection{Case study context description}

In order to evaluate this framework in an industrial context, we developed a case study together with our industrial partners. We use a lumber mill representative of the North American softwood lumber industry which normally produces standard NLGA products (commodity products).

We had access to about $1000 \log$ scans representative of the softwood supply of two different supply areas. The maximum quantities that can be supplied to the mill are respectively $350000 \mathrm{~m}^{3}$ for area 1 and $200000 \mathrm{~m}^{3}$ for area 2. Wood drying and planing (finishing) are not considered as we are focusing on sawmilling.

Some customers want products with specific characteristics that the mill has never produced before. The lumber company would like to know if it would be profitable for them to produce this particular product, as allowing the equipment to produce this product (by giving them new configuration settings) will lead to unknown variations about the quantity of other products which will be made at the same time. Moreover, when a contract is accepted there are minimum and maximum quantities as well as a calendar to observe. 
For this experiment, two non-NLGA speciality products are considered. The product 1.25x6 (with nominal dimensions of 1.25 inches thick and 6 inches wide) which is mainly used for building patios, and the $3 \times 3$ ( 3 inches thick and 3 inches wide) which is a product that is sometimes made for export. Those are products only made if some orders (contracts with a "sufficient" volume of products) are placed. A first customer would like to be delivered a volume ${ }^{3}$ of $200 \mathrm{Mfbm}$ of $1.25 \mathrm{x} 6$ during periods 10 to 15 . The second would also like $200 \mathrm{Mfbm}$ of $1.25 \times 6$ but during periods 24 to 29. The last one would like $150 \mathrm{Mfbm}$ of product $3 \times 3$ during periods 15 to 18 . A three-week production stop is mandatory on periods 29 to 31 . Prices of the commodity products fluctuate throughout the year according to lumber prices seasonality. Product prices used in the model are based on data given by one of our industrial partners and are shown in Figure 7.

For each period we have a maximal capacity of 70.9 worked hours for sawmilling ( 2 shifts per week). The maximum stock level of the finished product corresponds to the volume produced in about 5 production periods.

We use Optitek in order to simulate the sawing of the logs under the alternative operating settings in order to obtain information about the transformation process. The sawmill has been configured in order to make four different sets of products:

- Only the commodity products,

- The commodity and the $1.25 \times 6$ products,

- The commodity and the $3 \times 3$ products,

- The commodity, the $1.25 \times 6$ and the $3 \times 3$ products.

About 100 different alternative machine configurations within the plant representative of the main

\footnotetext{
${ }^{3}$ Board-foot is the unit of volume measurement used in North America; Mfbm = thousand foot board measure.
} 
settings were chosen for the simulation. The simulation of the sawing with each configuration to each possible set of products will lead to different quantities for each finished product (with the same raw material).

For each tuple < plant configuration, $\log$ provenance, possible set of products $>$, a simulation scenario is generated. Once all the possible combinations are simulated, the information about the transformation process is used as inputs in the tactical planning model (optimisation). An optimal 12-month (52 periods of one week) sales and production plan is therefore created. The plan takes into account all the parameters and decision variables shown in Section 4. It maximises the global benefits (and decides when to sell a product, when to keep it in inventory, which raw material to use, when to use a particular machine configuration, etc.). Consequently, the plan gives knowledge about which contract(s) (for speciality products) would be financially relevant to accept.

\subsection{Results and discussion}

Figure 8 summarises the tactical plan obtained. It shows, for each period, the raw material source to use, how the plant should be configured and when a speciality product should be produced. Two configurations are mainly used. Configuration 02 is employed with raw material from Area 2, configuration 56 with raw material from Area 1. This shows that it can be valuable to change the machine configurations of the mill when changing the supply. Moreover, the commodity products price seasonality makes the specialty product $1.25 \times 6$ relevant to be produced and delivered in periods 24 to 28 but not in periods 10 to 14 . The model never proposes to produce the $3 \times 3$. Indeed, it would not be financially interesting for the company to sell the $3 \times 3$ products.

For each period, the total volume produced is sensitively the same. However, the model modulates sales in order to exploit the stocking capacity as well as price fluctuation. Figure 9 shows when each commodity product is sold in order to maximize profit. 
One could ask what would happen if the company accepted all demands from customers for all specialty products. For the purpose of analysis, several tactical plans were produced by adding constraints into the model:

- Plan A: Plan for the original plant configuration (the initial plant configuration is used for each period without the possibility of producing any speciality products);

- Plan B: Optimal plan, obtained using our framework;

- Plan C: Plan without the possibility of producing any speciality products;

- Plan D: Plan with all 1.25x6 demand mandatory fulfilled;

- Plan E: Plan with all 3x3 demand mandatory fulfilled (1.25x6 were not to be fulfilled);

- Plan F: Plan with all 1.25x6 and 3x3 demand mandatory fulfilled (1.25x6 and 3x3 products had to be fulfilled by the model).

Figure 10 shows the improvement (or losses) associated to each plan when compared to the base case (Plan A). Plan B is the optimal plan (555 000 \$ improvement). Looking at Plan C (no specialty products at all), we can see its performance is very close to Plan B (only 15000 \$ less than Plan B). This is the additional value we get by allowing the production of specialty products. Plans D, E and F shows that not every demand for specialty products should be accepted despite their great selling prices.

\section{Conclusion}

The proposed simulation-optimisation framework allows finding the best combination of scenarios. It makes use of simulation to learn the output of several individual scenarios, and optimisation to find the best combination. It is intended for application to problems where sets of alternatives should be evaluated and selected at the same time, but the available simulation tool cannot do so. The relevance of the framework is demonstrated by solving a tactical planning problem in the softwood lumber industry. A log breakdown simulator and a tactical planning model are used in 
order to take into account new products opportunities and new raw material sources for Sales and Operations planning. Simulation enables finding the new mix of products resulting from the integration of a speciality product to the normal company mix of products, according to various plant and supply configurations. The tactical planning model considers these new options to create a multi-period tactical plan.

The impact of accepting or refusing demand for new products could lead to significant changes in benefits for the company. Our framework provides a tool for sawmills in order to check whether accepting a mid-term contract for a specific product is profitable or not. Our experiment highlights that adding a speciality product highly influences the changes in the mix of products and the whole set of products available for sale at each period. A speciality product made in a given period can lead to substantial value decrease but in another period can lead to improvement. It could actually be really expensive for the company to accept a demand for a particular product. The proposed tool makes it possible to quantify the impact of fulfilling a given demand and settle both the right price for each client and the raw material most suitable for production.

Lumber manufacturers are usually not comfortable with changing machines configurations. Indeed, this can lead to problems such as not enough lumber for planing (wood finishing operations), too much stock of a product at a given period in the year, etc. Using the framework, one can determine which configurations to use and when, while being assured of their effects. It also gives the ability to find the best configuration for a given raw material source for each period.

The studied Lumber Sales and Operations Planning case is not the only possible usage of the framework. It can also be used to solve other problems of the same type. For example, the framework could be applied to the supply chain network design problem, where simulation could be used to find out about individual plant designs performance, and optimisation to find the best combination and location for them according to market. We are now using it as well for hardwood 
flooring planning/scheduling problems. Simulation helps anticipate mill output according to machine configuration and raw material used. Optimisation specifies when to use each configuration according to demand plan.

\section{Aknowledgements:}

The authors would like to thank the FORAC Research Consortium, its partners and especially FPInnovations. Our gratitude goes as well to the Natural Sciences and Engineering Research Council of Canada (NSERC) who provided funding for this research.

\section{References}

Arabi, Mohsen, Jonathan Gaudreault, Mustapha Nourelfath, Jean Favreau, and Maxime MorneauPereira. 2012. Integrating Optimization and Simulation for Supply Chain Tactical Planning in the Forest Products Industry. Paper presented at the International Conference on Information Systems, Logistics and Supply Chain, Québec, Canada.

Bajgiran, Omid Sanei, Masoumeh Kazemi Zanjani, and Mustapha Nourelfath. 2014. Integrated tactical planning in lumber supply chains. Paper presented at the Industrial and Systems Engineering Research Conference, Montreal, Canada, May 31 - June 3.

Blackstone, John H. 2008. APICS Dictionary. Twelfth ed: APICS.

Carson, Yolanda, and Anu Maria. 1997. "Simulation Optimization: Methods And Applications." In Proceedings of the 1997 Winter Simulation Conference, 118-26.

Cid Yáñez, Fabian, Jean-Marc Frayret, François Léger, and Alain Rousseau. 2009. "Agent-based simulation and analysis of demand-driven production strategies in the timber industry." International journal of production research 47 (22):6295-319.

Crama, Yves, Yves Pochet, and Yannic Wera. 2001. "A Discussion of Production Planning Approaches in the Process Industry." In Core Discussion Paper. Liège, Belgium.

D'Amours, Sophie, Mikael Rönnqvist, and Andres Weintraub. 2008. "Using operational research for supply chain planning in the forest products industry." INFOR 46 (4):265-81.

$\mathrm{Fu}$, Michael C. 2015. Handbook of simulation optimization: Springer New York.

Gaudreault, Jonathan. 2009. "Algorithmes pour la prise de décision distribuée en contexte hiérarchique." PhD thesis, Ecole Polytechnique de Montreal.

Gaudreault, Jonathan, Pascal Forget, Jean-Marc Frayret, Alain Rousseau, Sébastien Lemieux, and Sophie D'Amours. 2010. "Distributed operations planning in the softwood lumber supply chain: Models and coordination." International Journal of Industrial Engineering: Theory Applications and Practice 17 (3):168-89.

Goldsman, David, and Barry L. Nelson. 1994. "Ranking, selection and multiple comparisons in computer simulation." In Proceedings of the 1994 Winter Simulation Conference, 192-9.

Kong, Jiehong, and Mikael Rönnqvist. 2014. "Coordination between strategic forest management and tactical logistic and production planning in the forestry supply chain." International Transactions in Operational Research 21 (5):703-35.

Ladier, Anne-Laure, Allen G. Greenwood, Gülgün Alpan, and Halston Hales. 2014. "Issues in the complementary use of simulation and optimization modeling." In Les Cahiers Leibniz.

Law, Averill M. 2007. Simulation modeling and analysis. 4th ed. Boston: McGraw-Hill.

Lindner, Berndt Gerald. 2014. "Determining optimal primary sawing and ripping machine settings in the wood manufacturing chain." Master, University of Stellenbosch.

Maness, T. C., and D. M. Adams. 1993. "The combined optimization of log bucking and sawing strategies." Wood and Fiber Science 23 (2):296-314. 
Maness, T. C., and S. E. Norton. 2002. "Multiple period combined optimization approach to forest production planning." Scandinavian Journal of Forest Research 17 (5):460-71.

Marier, Philippe, Stéphane Bolduc, Maha Ben Ali, and Jonathan Gaudreault. 2014. S\&OP network model for commodity lumber products. Québec, Canada: CIRRELT.

Rönnqvist, Mikael. 2003. "Optimization in forestry." Mathematical Programming 97 (1-2):267-84.

Sampson, Steve. 1990. "Modélisation graphique du débitage du bois." MSc Thesis, Université Laval.

Shahi, Shashi, and Reino Pulkki. 2013. "Supply Chain Network Optimization of the Canadian Forest Products Industry: A Critical Review." American Journal of Industrial and Business Management 3 (07):631.

Sinclair, M., and S. Erasmus. 1992. "A microcomputer-based decision support system for the management of lumber mill production." Computers \& Industrial Engineering 22 (4):43546.

Singer, M., and P. Donoso. 2007. "Internal supply chain management in the Chilean sawmill industry." International Journal of Operations \& Production Management 27 (5):524-41.

Turban, Efraim, Ramesh Sharda, and Dursun Delen. 2011. Decision support and business intelligence systems. 9th ed. Boston: Prentice Hall.

Vollmann, Thomas E., William L. Berry, and David C. Whybark. 1984. Manufacturing Planning and Control Systems. Homewood, IL: Irwin.

Wery, Jean, Philippe Marier, Jonathan Gaudreault, and André Thomas. 2014. "Decision-making framework for tactical planning taking into account market opportunities (new products and new suppliers) in a co-production context." In Proceedings of the 10th International Conference on Modeling, Optimization and SIMulation. Nancy, France.

Wessels, C. Brand, C. Price, P. Turner, and M. Dell. 2006. Integrating harvesting and sawmill operations using an optimized sawmill production planning system. Paper presented at the International Precision Forestry Symposium, Stellenbosch, South Africa, March 5-10. 


\section{List of figure captions}

Figure 1: Example of a production matrix, adapted from Gaudreault et al. (2010)

Figure 2: Example of a cutting pattern for a log after simulation using Optitek software

Figure 3: Operating principle of simulation-optimisation methods

Figure 4: Operating principle of the proposed method

Figure 5: Operating principle of the proposed framework when applied to the lumber market tactical planning problem

Figure 6: Inputs and outputs of the optimisation model

Figure 7: Product prices forecasts for the planning horizon

Figure 8: Results of the tactical planning

Figure 9: Volume of products sold

Figure 10: Plan value improvement results for several demands compared to the initial plant configuration plan value (Plan A) 